\title{
Occupational risk factors for male bladder cancer: results from a population based case cohort study in the Netherlands
}

\author{
M P A Zeegers, G M H Swaen, I Kant, R A Goldbohm, P A van den Brandt
}

\begin{abstract}
Objectives-This study was conducted to estimate risk of bladder cancer associated with occupational exposures to paint components, polycyclic aromatic hydrocarbons (PAHs), diesel exhausts, and aromatic amines among the general population in The Netherlands.
\end{abstract}

Methods-A prospective cohort study was conducted among 58279 men. In September 1986, the cohort members (55-69 years) completed a self administered questionnaire on risk factors for cancer including job history. Follow up for incident bladder cancer was established by linkage to cancer registries until December 1992. A case-cohort approach was used based on 532 cases and 1630 subcohort members. A case by case expert assessment was carried out to assign to the cases and subcohort members a cumulative probability of occupational exposure for each carcinogenic exposure. Results-Men in the highest tertiles of occupational exposure to paint components, PAHs, aromatic amines, and diesel exhaust had non-significantly higher age and smoking adjusted incident rate ratios (RRs) of bladder cancer than men with no exposure: 1.29 (95\% confidence interval (95\% CI) 0.71 to 2.33 ), 1.24 (95\% CI 0.68 to $2.27), 1.32$ (95\% CI 0.41 to 4.23 ) and 1.21 $(95 \%$ CI 0.78 to 1.88$)$, respectively. The associations between paint components and PAHs and risk of bladder cancer were most pronounced for current smokers. Among former smokers it seemed that for cumulative probability of exposure to paint components and PAHs, men who had smoked more than 15 cigarettes a day had RRs below unity compared with men who had smoked less than 15 cigarettes a day, whereas among current smokers the opposite was found. Exposure to diesel exhaust was positively associated with risk of bladder cancer among current and former smokers who had smoked more than 15 cigarettes a day.

Conclusions-This study provided only marginal evidence for an association between occupational exposure to paint components, PAHs, aromatic amines, and bladder cancer. Despite the small proportion of exposed subjects, an interaction with cigarette smoking was found, specifically for paint components, suggesting that the carcinogenic effect on the bladder might decrease after stopping smoking.

(Occup Environ Med 2001;58:590-596)

Keywords: bladder cancer; occupation; epidemiology

Bladder cancer is the most common urological cancer and is the seventh most common cancer among men, accounting for approximately 200000 new cases worldwide annually. ${ }^{1}$ Bladder cancer is considerably more common in men than in women (worldwide ratio is about 3.5:1), which by itself has been regarded as a possible indication for an occupational origin. ${ }^{2}$ The incidence of this cancer varies worldwide; in general, the highest incidence is found in North America and Europe. ${ }^{1}$

Bladder cancer has often been reported to be associated with occupational exposures. ${ }^{3}$ As early as the late 19th century doctors reported unusual incidences of bladder cancer in industry. ${ }^{4}$ In their classic study Case and Hosker ${ }^{5}$ reported an exceptionally high incidence of bladder cancer in the British rubber industry. They were some of the first epidemiologists to apply a retrospective cohort design to investigate the effect of occupational exposure to a possible carcinogen. ${ }^{5}$ Later several other agents or occupations have been associated with an increased risk of bladder cancer. Among these were exposure to polycyclic aromatic hydrocarbons (PAHs) in the aluminum, coal tar, and coal gasification industries. ${ }^{3}$ Also, several studies have reported an excess of bladder cancer among painters, ${ }^{6-9}$ although others could not confirm this association. ${ }^{10} 11$ Most epidemiological studies of the risk for bladder cancer among painters reported relative risks between 1.2 and $1.5 .^{3}$ In some studies increased risks of bladder cancer were found for increasing duration of exposure to paint components. ${ }^{12}{ }^{13}$ Finally, several epidemiological studies have reported more bladder cancer among lorry drivers, taxi drivers, and bus drivers. ${ }^{14-16}$ Overall relative risks for bladder cancer in studies of these occupational groups varied from 1.3 to 2.2. Most studies found positive trends with duration of exposure. ${ }^{3}$ The most likely causal agent is thought to be constituents of the diesel exhaust emissions. Again, these associations have not always been confirmed and are still a matter of debate.

Most epidemiological studies that investigated associations between specific occupational exposures and bladder cancer applied retrospective designs; sometimes prospective 
cohorts have been used. The possible confounding effects of exposure to other carcinogenic factors, such as cigarette smoking and dietary factors that are suspected of influencing the occurrence of bladder cancer were rarely taken into account. Epidemiological studies that did take into account the possible confounding effect of non-occupational exposures used case-control designs, possibly suffering from a recall bias, as data collection took place after the diagnosis of the disease. We have used data from The Netherlands cohort study - a prospective cohort study in the general population on diet, lifestyle, job history, and cancer-to study the relations between various occupational exposures and the incidence of bladder cancer, adjusting for the effects of several other risk factors.

Because of the nature of the database, which is not focused on any particular occupational group, we restricted the study to occupational exposures that were expected to be quite common in the general population. Occupational exposures that were thought to be very rare were regarded as being beyond the scope of this study. We focused the study on specific occupational exposures from which it was either expected that these exposures would be relatively common or that the relative risk for bladder cancer could be so high that this risk could be detected in a general population study. Therefore, we selected exposure to paint components, PAHs, diesel exhaust, and aromatic amines as potential risk factors for bladder cancer.

\section{Methods}

\section{STUDY POPULATION}

The study design, including data collection strategies, has been described in detail previously. ${ }^{17}$ In short, the cohort included 58279 men aged 55-69 at baseline. The study population originated from 204 municipal population registries throughout the Netherlands. The case-cohort approach was used for data processing and analysis. ${ }^{18}$ Cases were enumerated from the entire cohort, whereas the accumulated person-years in the cohort were estimated from a subcohort sample. Using this approach, a subcohort of 1688 men was randomly sampled from the cohort after baseline exposure measurement. The subcohort has been followed up for vital status information. No subcohort members were lost to follow up.

FOLLOW UP

Follow up for incident cancer was established by record linkage to cancer registries and the Dutch national database of pathology reports. ${ }^{19}$ The completeness of cancer follow up was estimated to be over $95 \% .^{20}$ The analysis was restricted to cancer incidence in 6.3 years of follow up, from September 1986 to December 1992. After excluding prevalent cases with cancer other than skin cancer a total of 1630 male subcohort members and 532 male incident cases with microscopically confirmed carcinomas of the urinary bladder, ureters, renal pelvis, or urethra were identified. Of these cases, 506 (95\%) were diagnosed with bladder cancer of which 490 (97\%) were transitional cell carcinomas. Because the overwhelming majority of tumours occurred in the urinary bladder and as the ureters, renal pelvis, and urethra are covered by the same urothelium as the urinary bladder, the term bladder cancer is used as a synonym for these neoplasms.

\section{EXPOSURE ASSESSMENT}

At baseline, the cohort members completed a posted, self administered questionnaire on potential confounders and other risk factors for cancer. In this questionnaire, job history was assessed by questions on job title, name of the company, type of the company, period, and information about what was being produced at the department. Experts in the fields of occupational epidemiology (GMHS) and occupational hygiene (IJK) assessed the probability of four carcinogenic exposures: paint components, PAHs, diesel exhaust, and aromatic amines without knowledge of the diseases of the subjects. ${ }^{21}$ Firstly, a list of all jobs in The Netherlands was independently reviewed. In this first examination all jobs with no potential carcinogenic exposures as already mentioned were excluded. Secondly, a more refined exposure assessment was conducted based on information about company name and type, period, and product, as the probability of carcinogenic exposure may differ between types of industry and between periods. Four exposure categories were defined: no exposure to the specific carcinogen, possible exposure (probability of exposure estimated to be lower than $30 \%$ ), probable exposure (probability of exposure between $30 \%$ and $90 \%$ ), and nearly certain exposure (probability of exposure over $90 \%$ ). Typical examples of high exposure classifications were: furniture maker, engraver, and maintenance painter for exposure to paint components; smith, coal miner, metal foundry worker, maintenance working in coking factory for exposure to PAHs; marine engineer, car mechanic, and lorry driver for exposure to diesel exhausts; and vulcaniser in rubber factory and cable factory worker for exposure to aromatic amines. As a measure of exposure, cumulative probability of exposure was calculated, which combines information about the probability of exposure and the duration of possible exposure. Therefore a weight was assigned to each exposure category: no exposure weight 0 ; possible exposure weight 0.15 ; probable exposure weight 0.6 ; and almost certain exposure weight 0.95 . Each weight corresponds to the midpoint of probability in each exposure category. The cumulative probability of exposure was calculated by multiplication of the weight given to each exposure category by the number of years exposed. Subsequently, for each person all weighted exposures were summed up for each of the four carcinogens separately and the exposed subjects were categorised in tertiles of exposure index.

\section{STATISTICAL ANALYSES}

Incidence rate ratios (RRs) and corresponding 95\% confidence intervals (95\% CI) for bladder 
Table 1 Distribution of categories of cumulative probability of exposure to paint components, polycyclic aromatic hydrocarbons (PAHs), diesel exhaust, and aromatic amines in men with bladder cancer (cases and subcohort members); Netherlands cohort study (1986-92)

\begin{tabular}{|c|c|c|c|c|}
\hline \multirow[b]{2}{*}{ Cumulative probability of exposure } & \multicolumn{2}{|c|}{ Cases $(n=619)$} & \multicolumn{2}{|c|}{ Subcohort $(n=1630)$} \\
\hline & $n$ & $\%$ & $n$ & $\%$ \\
\hline \multicolumn{5}{|l|}{ Paint components: } \\
\hline No exposure & 483 & 91.13 & 1494 & 92.00 \\
\hline Low exposure tertile & 8 & 1.51 & 43 & 2.65 \\
\hline Medium exposure tertile & 20 & 3.77 & 44 & 2.71 \\
\hline High exposure tertile & 19 & 3.58 & 43 & 2.65 \\
\hline \multicolumn{5}{|l|}{ PAHs: } \\
\hline No exposure & 488 & 92.60 & 1477 & 90.89 \\
\hline Low exposure tertile (low) & 7 & 1.33 & 51 & 3.14 \\
\hline Medium exposure tertile & 13 & 2.47 & 49 & 3.02 \\
\hline High exposure tertile & 19 & 3.61 & 48 & 2.95 \\
\hline \multicolumn{5}{|l|}{ Diesel exhaust: } \\
\hline No exposure & 428 & 81.37 & 1319 & 81.42 \\
\hline Low exposure tertile & 35 & 6.65 & 105 & 6.48 \\
\hline Medium exposure tertile & 31 & 5.89 & 96 & 5.93 \\
\hline High exposure tertile & 32 & 6.08 & 100 & 6.17 \\
\hline \multicolumn{5}{|l|}{ Aromatic amines: } \\
\hline No exposure & 522 & 98.31 & 1611 & 98.83 \\
\hline Low exposure & 3 & 0.56 & 10 & 0.61 \\
\hline High exposure & 6 & 1.13 & 9 & 0.55 \\
\hline
\end{tabular}

$\star$ Product of probability (weights $0.15,0.6$, and 0.95 ) and duration (y) of exposure.

cancer were estimated with exponentially distributed failure time regression models ${ }^{22}$ with the Stata statistical software package. ${ }^{23}$ Standard errors were estimated with the robust Hubert-White sandwich estimator to account for additional variance introduced by sampling from the cohort. This method is equivalent to the variance-covariance estimator presented by Barlow $^{24}$ and Lin and Ying. ${ }^{25}$ We confirmed constancy of the baseline hazard visually by plotting the natural logarithm of the baseline survival function against failure time.

Although cigarette smoking is assumed to be the most important risk factor for bladder cancer in general (RR 3.3, 95\% CI 2.6 to 4.2 for current $v$ never smoking), we also evaluated other potential risk factors for possible confounding effects based on earlier analyses. ${ }^{26-29}$ The following variables were considered as potential confounders: age (years), amount of cigarette smoking (cigarettes/day), duration of cigarette smoking (years of cigarette smoking), consumption of total fluid (ml/day), alcohol (g/day), coffee ( $\mathrm{ml} /$ day), tea ( $\mathrm{ml} /$ day), vegetables (g/day), fruit (g/day), and first degree family history of bladder cancer (yes or no). Those variables that showed a more than $10 \%$ influence on the risk of bladder cancer when considered in a multivariate model were included as covariates in multivariate analyses.

\section{Results}

Table 1 shows the distribution of the cumulative probability of exposure to each of the four carcinogens in the case and the subcohort group (table 1). The percentage of exposed people to paint components, PAHs, and diesel exhaust were roughly equal between cases and subcohort members. However, there were relatively more cases than subcohort members in the highest exposure tertiles. Cases were also more often exposed to aromatic amines than subcohort members (table 1).

The distribution of potential confounders for bladder cancer according to occupational exposure to paint components, PAHs, diesel exhaust, and aromatic amines is presented in table 2 . The confounders were equally distributed among never and ever exposed subcohort members for all investigated carcinogenic exposures. Exposure to paint components was correlated with exposure to PAHs and diesel exhaust. Diesel exhaust was furthermore correlated with PAHs and aromatic amines (table 2).

Table 3 shows the associations of occupational exposure to risk of bladder cancer. The incidence rate ratio for bladder cancer adjusted for age and cigarette smoking was 1.29 (95\% CI 0.71 to 2.33 ) comparing the highest tertile of exposure to paint components with no occupational exposure ( $\mathrm{p}$ value for trend 0.08 ). After additional adjustment for other occupational exposures, the RR changed to 1.31 (95\% CI 0.72 to 2.40 , $\mathrm{p}$ value for trend 0.09 ). Men with a higher exposure to aromatic amines were also found to be at increased risk of bladder cancer, but the estimates were based on small numbers (adjusted for age and smoking RR $1.32,95 \%$ CI 0.41 to 4.23$)$. The corresponding RR was 1.36 (95\% CI 0.42 to 4.35 ) after adjustment for age, smoking, and occupation. Exposure to PAHs or diesel exhaust did not substantially increase the risk of bladder cancer ( $\mathrm{p}$ value for trend 0.80 and 0.50 , respectively). Men in the highest exposure categories of

Table 2 Association between possible confounders and occupational exposure in the subcohort; Netherlands cohort study (1986-92)

\begin{tabular}{|c|c|c|c|c|c|c|c|c|}
\hline \multirow[b]{3}{*}{ Variables } & \multicolumn{8}{|c|}{ Occupational exposure to: } \\
\hline & \multicolumn{2}{|c|}{ Paint components } & \multicolumn{2}{|l|}{ PAHs } & \multicolumn{2}{|c|}{ Diesel exhaust } & \multicolumn{2}{|c|}{ Aromatic amines } \\
\hline & Never & Ever & Never & Ever & Never & Ever & Never & Ever \\
\hline \multicolumn{9}{|l|}{ Potential confounders: } \\
\hline Age (mean, y) & 61.40 & 61.28 & 61.45 & 60.74 & 61.44 & 61.16 & 61.38 & 62.37 \\
\hline Smoking amount (mean, cigarettes/day) ${ }^{\star}$ & 16.95 & 16.73 & 16.90 & 17.33 & 16.90 & 17.00 & 16.96 & 15.89 \\
\hline Smoking duration (mean, y) ${ }^{\star}$ & 33.62 & 33.58 & 33.64 & 32.90 & 33.75 & 33.07 & 33.58 & 33.83 \\
\hline Total fluid consumption (mean, 1/day) & 2124 & 2151 & 2127 & 2115 & 2114 & 2178 & 2125 & 2153 \\
\hline Alcohol consumption (mean, g/day) & 14.42 & 14.84 & 14.39 & 15.01 & 14.60 & 13.53 & 14.43 & 16.65 \\
\hline Coffee consumption (mean, cups/day) & 45.53 & 47.76 & 45.52 & 47.39 & 45.02 & 48.64 & 45.71 & 46.32 \\
\hline Tea consumption (mean, cups/day) & 24.78 & 23.83 & 25.09 & 20.75 & 24.90 & 23.69 & 24.65 & 27.37 \\
\hline Vegetable consumption (g/day) & 189.8 & 182.6 & 188.0 & 201.5 & 186.3 & 201.6 & 188.8 & 218.5 \\
\hline Fruit consumption (g/day) & 152.6 & 138.2 & 151.3 & 154.7 & 149.2 & 161.8 & 151.3 & 165.5 \\
\hline \multicolumn{9}{|l|}{ Exposure to: } \\
\hline Paint components (\% ever) & 0.00 & 100.00 & 5.13 & 40.76 & 5.19 & 21.57 & 8.19 & 7.14 \\
\hline PAHs ( $\%$ ever) & 5.56 & 42.86 & 0.00 & 100.00 & 4.03 & 28.68 & 8.53 & 14.29 \\
\hline Diesel exhaust (\% ever) & 15.82 & 48.57 & 14.43 & 61.75 & 0.00 & 100.00 & 18.29 & 32.14 \\
\hline Aromatic amines ( $\%$ ever) & 1.32 & 1.14 & 1.23 & 2.17 & 1.09 & 2.28 & 0.00 & 100.00 \\
\hline
\end{tabular}

* Only for current and former cigarette smokers.

PAHs=polycyclic aromatic hydrocarbons. 
Table 3 Incidence rate ratios (RRs) for bladder cancer according to occupational exposures in age adjusted and multivariable analysis; Netherlands cohort study (1986-92)

\begin{tabular}{|c|c|c|c|c|c|}
\hline Life time exposure index* & Cases & $\begin{array}{l}\text { Subcohort } \\
\text { (person-years) }\end{array}$ & $R R(95 \% C I) \dagger$ & $R R(95 \% C I) \neq$ & $R R(95 \% C I) S$ \\
\hline \multicolumn{6}{|l|}{ Paint components: } \\
\hline No exposure & 483 & 8967 & 1.00 (reference) & 1.00 (reference) & 1.00 (reference) \\
\hline Low exposure tertile & 8 & 258 & $0.67(0.31$ to 1.44$)$ & $0.74(0.33$ to 1.68$)$ & $0.75(0.33$ to 1.72$)$ \\
\hline Medium exposure tertile & 20 & 262 & $1.37(0.79$ to 2.39$)$ & $1.76(0.96$ to 3.24$)$ & $1.78(0.94$ to 3.37 \\
\hline High exposure tertile & 19 & 257 & $1.23(0.71$ to 2.14$)$ & $1.29(0.71$ to 2.33$)$ & $1.31(0.72$ to 2.40$)$ \\
\hline $\mathrm{p}$ Value for trend & & & 0.25 & 0.08 & 0.09 \\
\hline \multicolumn{6}{|l|}{ PAHs: } \\
\hline No exposure & 488 & 8864 & 1.00 (reference) & 1.00 (reference) & 1.00 (reference) \\
\hline Low exposure tertile & 7 & 303 & $0.47(0.21$ to 1.04$)$ & $0.47(0.21$ to 1.06$)$ & $0.51(0.22$ to 1.19$)$ \\
\hline Medium exposure tertile & 13 & 298 & $0.85(0.45$ to 1.59$)$ & $0.85(0.44$ to 1.62$)$ & $0.97(0.49$ to 1.90$)$ \\
\hline High exposure tertile & 19 & 286 & $1.24(0.72$ to 2.13$)$ & $1.24(0.68$ to 2.27$)$ & $1.18(0.62$ to 2.24$)$ \\
\hline $\mathrm{p}$ Value for trend & & & 0.98 & 0.80 & 0.85 \\
\hline \multicolumn{6}{|l|}{ Diesel exhaust: } \\
\hline No exposure & 428 & 7910 & 1.00 (reference) & 1.00 (reference) & 1.00 (reference) \\
\hline Low exposure tertile & 35 & 643 & $1.00(0.68$ to 1.51$)$ & $0.98(0.64$ to 1.51$)$ & $1.00(0.65$ to 1.54$)$ \\
\hline Medium exposure tertile & 31 & 580 & $0.99(0.65$ to 1.52$)$ & $0.98(0.62$ to 1.55$)$ & $0.96(0.60$ to 1.53$)$ \\
\hline High exposure tertile & 32 & 586 & $1.07(0.70$ to 1.62$)$ & $1.21(0.78$ to 1.88$)$ & $1.17(0.74$ to 1.84$)$ \\
\hline $\mathrm{p}$ Value for trend & & & 0.78 & 0.50 & 0.76 \\
\hline \multicolumn{6}{|l|}{ Aromatic amines: } \\
\hline No exposure & 522 & 9660 & 1.00 (reference) & 1.00 (reference) & 1.00 (reference) \\
\hline Low exposure & 3 & 63 & $0.77(0.21$ to 2.85$)$ & $0.63(0.12$ to 3.13$)$ & $0.64(0.13$ to 3.22$)$ \\
\hline High exposure & 6 & 54 & $2.00(0.68$ to 5.88$)$ & $1.32(0.41$ to 4.23$)$ & $1.36(0.42$ to 4.35$)$ \\
\hline $\mathrm{p}$ Value for trend & & & 0.24 & 0.78 & 0.72 \\
\hline
\end{tabular}

*Product of probability (weights $0.15,0.6$, and 0.95$) \times$ duration $(y)$ of exposure.

†Adjusted for age.

¥Adjusted for age, cigarette smoking amount (cigarettes/day), and cigarette smoking duration (y).

\Adjusted for age, other occupational exposures, cigarette smoking amount (cigarettes/day), and cigarette smoking duration (y).

$\mathrm{PAHs}=$ polycyclic aromatic hydrocarbons.

PAHs had non-significantly higher risks of bladder cancer than men with no occupational exposure to PAHs (adjusted for age and smoking RR $1.24,95 \%$ CI 0.68 to 2.27 ) and diesel exhaust (adjusted for age and smoking RR $1.21,95 \%$ CI 0.78 to 1.88 ). After adjustment for other occupational exposures and cigarette smoking the RRs changed to 1.18 (95\% CI 0.62 to 2.24 ) and 1.17 (95\% CI 0.74 to 1.84 ), respectively (table 3 ). Additional correction for total fluid, alcohol, coffee, tea, vegetables, and fruit consumption did not essentially change the risk estimates for the carcinogenic exposures (data not shown).

The associations between cumulative probability of exposure to paint components and PAHs, and risk of bladder cancer were more explicit for current smokers than for never or former smokers (table 4). It was not possible to stratify exposure to aromatic amines on characteristics of cigarette smoking, because of sparcity of data. Among the former smokers it seemed that men who smoked more than 15 cigarettes a day had lower RRs for exposure to paint components and PAHs compared with men who had smoked less than 15 cigarettes daily, whereas among current smokers the opposite was found. The positive association between paint components, PAHs, and risk of bladder cancer increased by increasing number of cigarettes smoked among current smokers. Exposure to diesel exhaust was positively associated with risk of bladder cancer among current smokers and among men who smoked more than 15 cigarettes a day, irrespective of smoking habit (table 4).

The positive association between cumulative probability of exposure to paint components and transitional cell carcinoma of the bladder was similar for papillary and non-papillary (invasive) tumours. A positive association between exposure to PAHs and risk of bladder cancer was most pronounced in non-papillary invasive transitional cell carcinomas of the urinary bladder. The positive association between cumulative probability of exposure to diesel

Table 4 Incidence rate ratios for bladder cancer for occupational exposures (ever exposed $v$ non-exposed (exp v non)) stratified upon cigarette smoking habit and cigarette smoking amount; Netherlands cohort study (1986-92)

\begin{tabular}{|c|c|c|c|c|c|c|}
\hline \multirow[b]{2}{*}{ Cigarette smoking } & \multicolumn{2}{|c|}{ Paint components } & \multicolumn{2}{|l|}{$P A H^{\star}$} & \multicolumn{2}{|l|}{ Diesel exhaust } \\
\hline & $\begin{array}{l}\text { Cases } \\
(\exp v \text { non })^{*}\end{array}$ & $R R(95 \% C I) \dagger$ & $\begin{array}{l}\text { Cases } \\
(\exp v \text { non })^{*}\end{array}$ & $R R(95 \% C I) \dagger$ & $\begin{array}{l}\text { Cases } \\
(\exp v \text { non) }\end{array}$ & $R R(95 \% C I)+$ \\
\hline Never smoker $\$$ & $2 / 34$ & $1.35(0.26$ to 7.12$)$ & $0 / 36$ & Too few cases & $2 / 34$ & $0.51(0.11$ to 2.35$)$ \\
\hline \multicolumn{7}{|l|}{ Smoking status } \\
\hline Former ${ }^{\star \star}$ & $13 / 223 \ddagger$ & 0.65 (0.34 to 1.26$)$ & $15 / 221 \ddagger$ & $0.67(0.36$ to 1.27$)$ & $46 / 190 \ddagger$ & $1.01(0.68$ to 1.49$)$ \\
\hline$<15 \dagger$ cigarettes/day $+\dagger$ & $5 / 64$ & $1.13(0.37$ to 3.43$)$ & $4 / 64$ & $0.59(0.19$ to 1.79$)$ & $7 / 61$ & $0.38(0.11$ to 1.28$)$ \\
\hline$\geqslant 15 \dagger$ cigarettes/day $+\dagger$ & $8 / 151$ & $0.42(0.17$ to 1.03$)$ & $11 / 149$ & $0.25(0.00$ to 4.28$)$ & $38 / 122$ & $1.37(0.74$ to 2.56$)$ \\
\hline 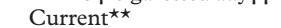 & $32 / 223 \ddagger$ & $2.22(1.15$ to 4.29$)$ & $24 / 228 \ddagger$ & $1.16(0.60$ to 2.23$)$ & $50 / 201 \ddagger$ & $1.24(0.81$ to 1.90$)$ \\
\hline$<15 \dagger$ cigarettes/day $+\dagger$ & $9 / 65$ & $1.40(0.50$ to 3.93$)$ & $7 / 67$ & $1.37(0.25$ to 7.44$)$ & $15 / 57$ & $0.99(0.41$ to 2.43$)$ \\
\hline$\geqslant 15+$ cigarettes/daytt & $20 / 129$ & 3.53 (1.52 to 8.22$)$ & $16 / 131$ & $1.61(0.62$ to 4.17$)$ & $29 / 119$ & $1.22(0.63$ to 2.39$)$ \\
\hline
\end{tabular}

*Number of exposed and non-exposed bladder cancer cases included in the analysis.

tAdjusted for age and other occupational exposures.

$\ddagger$ The numbers of exposed and non-exposed cases in the strata of cigarette smoking amount might not add up due to missing data on the number of cigarettes smoked per day.

$\S T h e$ reference category $(R R=1.0)$ is formed by subjects not exposed to the corresponding occupational risk factor.

${ }^{\star \star}$ Adjusted for age, other occupational exposures, cigarette smoking amount (cigarettes/day), and cigarette smoking duration (y).

††Adjusted for age, other occupational exposures, and cigarette smoking duration (y).

$\mathrm{PAHs}=$ polycyclic aromatic hydrocarbons. 
Table 5 Incidence rate ratios (RRs) for male transitional cell carcinoma of the urinary bladder for occupational exposures (non-exposed $v$ ever exposed)f or tumour invasiveness and morphology; Netherlands cohort study (1986-92)

\begin{tabular}{|c|c|c|c|c|}
\hline \multirow[b]{2}{*}{ Probability of exposure } & \multicolumn{2}{|c|}{ Non-invasive $\left(T_{I S} / T_{a} / T_{\nu}\right)$} & \multicolumn{2}{|l|}{ Invasive $T_{2-4}$} \\
\hline & $\begin{array}{l}\text { Non-papillary } \\
(n=28)^{\star} \\
R R(95 \% C I) \neq\end{array}$ & $\begin{array}{l}\text { Papillary } \\
(n=248) \dagger \\
R R(95 \% C I) \neq\end{array}$ & $\begin{array}{l}\text { Non-papillary } \\
(n=122)^{\star} \\
R R(95 \% C I) \neq\end{array}$ & $\begin{array}{l}\text { Papillary } \\
(n=162) \dagger \\
R R(95 \% C I) \neq\end{array}$ \\
\hline Paint components & Too few cases & 1.45 (0.83 to 2.53$)$ & 1.34 (0.69 to 2.62$)$ & $1.18(0.54$ to 2.56$)$ \\
\hline PAHs & Too few cases & $0.69(0.34$ to 1.43$)$ & $1.59(0.77$ to 3.28$)$ & $0.51(0.19$ to 1.36$)$ \\
\hline Diesel exhaust & $1.72(0.51$ to 5.82$)$ & $0.82(0.49$ to 1.36$)$ & $1.07(0.54$ to 2.12$)$ & $1.17(0.65$ to 2.12$)$ \\
\hline
\end{tabular}

^ICD-O:M8120.

+ICDO:M8130.

¥Adjusted for age, other occupational exposures, cigarette smoking amount (cigarettes/day), and duration of cigarette smoking (y). $\mathrm{PAHs}=$ polycyclic aromatic hydrocarbons.

exhaust and risk of bladder cancer was most pronounced among men with non-papillary non-invasive tumours (table 5). Subgroup analyses for exposure to aromatic amines and tumour invasiveness and morphology were not possible because too few cases were exposed to aromatic amines.

\section{Discussion}

In this study we examined the association between four occupational exposures and the incidence of bladder cancer. The results suggest a possible positive association between cumulative exposure to paint components, PAHs, and aromatic amines and the incidence of bladder cancer, although significance was not reached. The broad $95 \%$ CIs might reflect the relatively few exposed cases in this study or random error in exposure assessment. Only very limited support, if any, was found for an association between diesel exhaust and the risk of bladder cancer. If there is an association between diesel exhaust and bladder cancer at all, the results indicate that it may be limited to non-papillary, non-invasive bladder cancer. Statistical adjustment for the effect of other potential risk factors tended rather to increase the RRs than to decrease the estimates.

Many studies on occupational risk factors for bladder cancer have been conducted. ${ }^{30}$ For the most part, epidemiological evidence has been derived from either job titles (obtained through a job exposure matrix (JEM)) or self assessed exposures to certain agents. In only a few studies a case by case expert evaluation of exposure to occupationally related agents was performed. $^{8}{ }^{31-34}$ The quality of the exposure assessment strongly affects the outcome of the risk estimate ${ }^{35}$ and ideally includes both intensity and duration of the occupational exposure for each specific study subject. However, in large population based studies it is almost impossible to obtain this quantitative information. Moreover, in this type of study the range of jobs with potential exposures is large and within given jobs there is a large variation in exposures. This makes it even more difficult to identify a clear link between jobs and exposures compared with industry based studies. ${ }^{36}$ Self assessment of occupational exposures is considered inadequate as the chemical knowledge of the study participants in general is not sufficient for a valid recall of agent specific, time specific worksite exposures. ${ }^{25}$ In our study only the occupational history of the study subjects was available, which does not allow an estimation of the actual exposure concentrations that were experienced in the past. The highest achievable was a retrospective exposure assessment of probability of exposure. ${ }^{21}$ In general this can be obtained through a JEM or a case by case expert assessment. Both techniques have been used in studies on occupational risk factors for bladder cancer. ${ }^{30}$ In this study a case by case expert assessment was used. ${ }^{21}$ The main advantage of this method, compared with the use of a JEM, is that all the available information (job title, type of the company, products, and period) is used for the exposure assessment ${ }^{36}{ }^{37}$ whereas the agent specific and time specific information derived from a JEM is limited. ${ }^{30}{ }^{36}$ Also the case by case expert assessment provides the option to use information on the name of the company where the study subject worked to further specify the exposure assessment. For example, a maintenance worker in a metal processing company would be classified by a JEM as not exposed to PAHs. However, if it is known that the person worked for ALDEL, an aluminum smelter, it is clear that the maintenance worker has probably been exposed to PAHs, as aluminum smelters contain pot rooms. Therefore, a JEM may produce more non-differential misclassification than exposure assessments by experts. ${ }^{36}{ }^{37}$ However, with a case by case expert assessment in general there are no explicit definitions of the criteria, which are used for the assessment of exposure, ${ }^{37}$ and that assessment is affected by the degree of learning of the experts. Therefore, a case by case expert assessment may be less reproducible than a JEM, which will produce the same exposure information for identical basic data. To improve reliability, we used a two stage exposure assessment in which two experts independently assessed the exposure. Disagreements were solved through consensus meetings.

The database available for the analysis provided us with the opportunity to test the possible effect of other risk factors, in particular cigarette smoking, on the observed associations. We modelled cigarette smoking habits so that they best explained bladder cancer. ${ }^{26}$ This resulted in a model including number of years smoked and habitual number of cigarettes smoked each day, both as continuous variables. We therefore think that the associations found were not entirely due to residual confounding by smoking, although we cannot exclude some effect. We were not able to explain our results on the basis of confounding of other factors as 
well as cigarette smoking, as the results were essentially unchanged after incorporating into the analyses known or suspected risk factors for bladder cancer, including total consumption of fluid, alcohol, coffee, tea, vegetables, and fruit.

After stratifying the study population into non-smokers, former smokers, and current smokers a pattern emerged indicating that the effects of the occupational exposures were confined to the current smokers. The RR of cumulative probability of exposure to paint components for bladder cancer in former smokers was 0.65 , by contrast with an RR of 2.22 for current smokers. This was significant. A further breakdown of these groups into light smokers and heavy smokers showed a pattern consistent with a stronger association in current smokers who smoked more than 15 cigarettes a day compared with those who smoked less often. The interaction found might represent some form of biological synergy between cigarette smoking and exposure to aromatic amines and PAHs in bladder cacinogenesis, as some types of these compounds (naphthylamine and benzo[a]pyrene, respectively) are formed when tobacco is smoked. These results also show that current rather than former smoking might play a part in occupational carcinogenesis of bladder cancer. This effect was particularly clear for exposure to paint components and to a lesser extent for exposure to PAHs. Therefore, workers exposed to paint components even only in the past might be advised to refrain from smoking cigarettes. However it must be pointed out that as the information on amount of cigarette smoking was not always complete, the stratified estimates might possibly be overestimated especially among the current smokers. Also, despite the substantial size of this cohort study the number of cases limited the possibilities for further breakdowns and stratifications that are involved in subgroup analyses.

Several other researchers have reported possible interactions between smoking and the association between occupational exposures and risk of bladder cancer. Schumacher et $a l^{88}$ reported an interaction between exposure to aromatic amines and bladder cancer with smoking. The odds ratio for never smokers exposed to aromatic amines for 10 or more years was 1.65 , for non-exposed current smokers 3.57 and for current smokers exposed to aromatic amines 6.74. From further modelling the researchers concluded that the study gave support for some deviation from the additive model. Several other studies investigated the risks of bladder cancer from occupational exposures and cigarette smoking, but no analyses were done to test interaction between smoking and occupational exposures. ${ }^{39} 40$

In conclusion, our study provides only marginal evidence for an association between occupational exposure to paint components, PAHs, aromatic amines, and risk of bladder cancer. It further shows, despite the small proportion of exposed subjects in the study, that there might be a potentially important interactive effect from cigarette smoking, specifically for paint components, suggesting that the carcinogenic effect might decrease after stopping smoking.

The Netherlands cohort study was supported by the Dutch Cancer Society. We thank the regional cancer registries, the Dutch national database of pathology reports (PALGA), and the National Health Care Information Center for providing incidence data; $S$ Van de Crommert, $H$ Brants, W van Dijk, $M$ Moll, J Nelissen, C de Zwart, A Pisters, H van Montfort, R Schmeitz, $T$ van Montfort, T van Moergastel, and E Geuskens for assistance.

1 Parkin DM, Vizcaino AP, Skinner ME, et al. Cancer patterns and risk factors in the African population of southwestern Zimbabwe, 1963-77. Cancer Epidemiol Biomarkers Prev 1994;3:537-47.

2 Lilienfeld AM, Lilienfeld DE. foundations of epidemiology. New York Oxford: Oxford University Press, 1980.

3 Schottenfeld D, Fraumeni JF. Cancer epidemiology and prevention. Oxford: Oxford University Press, 1996.

4 Rehn L. Blasengeschwuelste bei Fuchsin-arbeitern. Arch Klin Chir 1895;50:588-600.

5 Case RAM, Hosker ME. tumour of the urinary bladder as an occupational disease in the rubber industry in England an occupational disease in the rubber industry

6 Matanoski GM, Stockwell HG, Diamond EL, et al. A cohort mortality study of painters and allied tradesmen. Scand $\mathcal{F}$ Work Environ Health 1986;12:16-21.

7 Bethwaite PB, Pearce N, Fraser J. Cancer risks in painters: study based on the New Zealand Cancer Registry. Br f Ind Med 1990;47:742-6.

8 Siemiatycki J, Dewar R, Nadon L, et al. Occupational risk factors for bladder cancer: results from a case-control study in Montreal, Quebec, Canada. Am f Epidemiol 1994;140: 1061-80.

9 Terstegge CW, Swaen GM, Slangen JJ, et al. Mortality patterns among commercial painters in The Netherlands. Int $\mathcal{F}$ Occup Environ Health 1995;1:303-10.

10 Englund A. Cancer incidence among painters and some allied trades. F Toxicol Environ Health 1980;6:1267-73.

11 Morrison AS, Ahlbom A, Verhoek WG, et al. Occupation and bladder cancer in Boston, USA, Manchester, UK, and and bladder cancer in Boston, USA, Manchester, UK, and Nagoya, Jap

12 Jensen OM, Wahrendorf J, Knudsen JB, et al. The Copenhagen case-referent study on bladder cancer. Risks among drivers, painters and certain other occupations. Scand $\mathcal{F}$ Work Environ Health 1987;13:129-34.

13 Silverman DT, Levin LI, Hoover RN, et al. Occupational risks of bladder cancer in the United States: I. White men. $\mathcal{f}$ Natl Cancer Inst 1989;81:1472-80.

14 Baxter PJ, McDowall ME. Occupation and cancer in London: an investigation into nasal and bladder cancer using the cancer atlas. $B r$ F Ind Med 1986;43:44-9.

15 Claude JC, Frentzel Beyme RR, Kunze E. Occupation and risk of cancer of the lower urinary tract among men. A case-control study. Int 7 Cancer 1988;41:371-9.

16 Steenland K, Burnett C, Osorio AM. A case-control study of bladder cancer using city directories as a source of occuof bladder cancer using city directories as a source

17 van den Brandt PA, Goldbohm RA, van het Veer P AV, et al. A large-scale prospective cohort study on diet and cancer in A large-scale prospective cohort study on diet and can

18 Prentice RL. A case-cohort design for epidemiologic cohort studies and disease prevention trials. Biometrika 1986;73: $1-11$

19 van den Brandt PA, Schouten LJ, Goldbohm RA, et al. Development of a record linkage protocol for use in the Dutch cancer registry for epidemiological research. Int $\mathcal{F}$ Epidemiol 1990;19:553-8.

20 Goldbohm RA, van den Brandt PA, Dorant E. Estimation of the coverage of Dutch municipalities by cancer registries and PALGA based on hospital discharge data. Tijdschr Soc Gezond 1994;72:80-4.

21 van Loon AJ, Kant IJ, Swaen GM, et al. Occupational exposure to carcinogens and risk of lung cancer: results from The Netherlands cohort study. Occup Environ Med 1997;54:817-24.

22 Volovics A, van den Brandt PA. Methods for the analyses of

23 StataCorp. Stata statistical software: release 6.0. College StataCorp. Stata statistical software:
Station, TX: Stata Corporation, 1999.

24 Barlow WE. Robust variance estimation for the case-cohort design. Biometrics 1994;50:1064-72.

25 Lin DY, Ying Z. Cox regression with incomplete covariate measurements. Fournal of the American Statistical Association 1993;88:1341-9.

26 Zeegers MP, Tan FE, Dorant E, et al. The impact of characteristics of cigarette smoking on urinary tract cancer risk: a meta-analysis of epidemiologic studies. Cancer 2000;89: 630-9.

27 Zeegers MPA, Tan FES, Goldbohm RA, et al. Are coffee and tea consumption associated with urinary tract cancer risk: a systematic review and meta-analysis. Int $\mathcal{f}$ Epidemiol 2000 (in press).

28 Zeegers MP, Tan FE, Verhagen AP, et al. Elevated risk of cancer of the urinary tract for alcohol drinkers: a meta-analysis. Cancer Causes Control 1999;10:445-51.

29 Steinmaus CM, Nunez S, Smith AH. Diet and bladder cancer: a meta-analysis of six dietary variables. Am f Epidemiol 2000;151:693-702. 
30 Pesch B, Haerting J, Ranft U, et al. Occupational risk factors for urothelial carcinoma: agent-specific results from a casecenter urothelial and renal cancer. Int f Epidemiol 2000;29. $238-47$

31 Bonassi S, Merlo F, Pearce N, et al. Bladder cancer and occupational exposure to polycyclic aromatic hydrocarbons. Int 7 Cancer 1989;44:648-51.

32 Cordier S, Clavel J, Limasset JC, et al. Occupational risks of bladder cancer in France: a multicentre case-control study. Int $\mathcal{F}$ Epidemiol 1993;22:403-11.

33 Clavel J, Mandereau L, Limasset JC, et al. Occupational exposure to polycyclic aromatic hydrocarbons and the risk of bladder cancer: a French case-control study. Int f Epidemiol 1994;23:1145-53.

34 Hours M, Danache B, Fevotte J, et al. Bladder cancer and occupational exposures. Scand $\mathcal{F}$ Work Environ Health 1994; 20:322-30.
35 Dosemeci M, Cocco P, Gomez M, et al. Effects of three features of a job-exposure matrix on risk estimates. Epidemiology 1994;5:124-7.

36 Bouyer J, Hemon D. Retrospective evaluation of occupational exposures in population-based case-control studies: general overview with special attention to job exposure matrices. Int F Epidemiol 1993;22:S57-64.

37 Bouyer J, Hemon D. Studying the performance of a job exposure matrix. Int f Epidemiol 1993;22:S65-71.

38 Schumacher MC, Slattery ML, West DW. Occupation and bladder cancer in Utah. Am F Ind Med 1989;16:89-102.

39 Burns PB, Swanson GM. Risk of urinary bladder cancer among blacks and whites: the role of cigarette use and occupation. Cancer Causes Control 1991;2:371-9.

40 Porru S, Aulenti V, Donato F, et al. Bladder cancer and occupation: a case-control study in northern Italy. Occup Environ Med 1996;53:6-10.

\title{
Narrative Based Medicine, An Interdisciplinary Conference
}

\author{
Research, Narrative, and Practice
}

A two day conference-Monday 3rd and Tuesday 4th September 2001

\section{Homerton College, Cambridge, UK}

\section{BMF Publishing Group}

For full details contact: BMA/BMJ Conference Unit, Tavistock Square, London, WC1H 9JP Tel: +44 (0)20 7383 6819; fax: +44 (0)20 7383 6663; email: clyders@bma.org.uk.

www.quality.bmjpg.com 